\title{
Correction to: How Responsive are Anesthesiologists to Patient Pain? Residents' Verbal and Nonverbal Responses to Standardized Patient Pain Cues
}

\author{
Mollie A. Ruben ${ }^{1,2}$ (D) Danielle Blanch-Hartigan ${ }^{3}$. Jill Laquidara4 ${ }^{4}$ Elaine C. Meyer ${ }^{5,6}$. \\ Judith A. Hall ${ }^{7}$. David Waisel ${ }^{8,9} \cdot$ Richard Blum $^{5,6}$
}

Published online: 22 November 2021

(c) Springer Science+Business Media, LLC, part of Springer Nature 2021

\section{Correction to: Journal of Nonverbal Behavior https://doi.org/10.1007/s10919-021-00390-2}

The original version of this article unfortunately contained a mistake. In the acknowledgements section, a sentence read incorrectly as 'there are conflicts of interest', it should have read as 'there are no conflicts of interest'.

In the methods section under the heading 'Participants', the first line read as 'A total of 65 videotaped interactions between first-year $(\mathrm{N}=49,59 \%)$ and third-year $(\mathrm{N}=16,19 \%)$ anesthesiology residents' instead it should have read as 'A total of 65 videotaped interactions between first-year $(\mathrm{N}=49,75 \%)$ and third-year $(\mathrm{N}=16,25 \%)$ anesthesiology residents'.

The original article has been corrected.

Publisher's Note Springer Nature remains neutral with regard to jurisdictional claims in published maps and institutional affiliations.

The original article can be found online at https://doi.org/10.1007/s10919-021-00390-2.

Mollie A. Ruben

mollie.ruben@maine.edu

https://umaine.edu

Psychology Department, University of Maine, 301 Little Hall, Orono, ME 04469, USA

2 US Department of Veterans Affairs, Boston, MA, USA

3 Bentley University, Waltham, MA, USA

4 Lesley University, Cambridge, MA, USA

5 Boston Children's Hospital and Center for Bioethics, Boston, MA, USA

6 Harvard Medical School, Boston, MA, USA

7 Northeastern University, Boston, MA, USA

8 Yale New Haven Children's Hospital, New Haven, CT, USA

9 Yale School of Medicine, New Haven, CT, USA 